\title{
Changing perspectives on liquid nitrogen use and storage
}

\author{
Lucia De Santis ${ }^{1}$ (1) - Lodovico Parmegiani ${ }^{2}$. Catello Scarica ${ }^{3} \cdot$ On behalf of SIERR, Italian Society of Embryology \\ Reproduction and Research
}

Received: 28 January 2021 / Accepted: 3 February 2021 / Published online: 10 February 2021

(C) The Author(s), under exclusive licence to Springer Science+Business Media, LLC part of Springer Nature 2021

\section{Dear Editor,}

We read with interest the article of Porcu and colleagues regarding the use of high-security closed devices to protect human oocytes from potential risk of viral contamination during the COVID-19 pandemic. Prospective studies demonstrating equal effectiveness of vitrification systems are warmly welcome, and we congratulate the authors for achieving this purpose.

The safety of cryopreservation in the context of reproductive medicine is a crucial topic to mitigate any risk of cross-infection. In relation to this, in their article, the authors declare that the liquid nitrogen is a potential source of pathogens; we completely agree with the authors, but we would also like to point out that liquid nitrogen and nitrogen vapor (LN2/NV) themselves can potentially be a risk as a source of infection. The contamination of LN2/ $\mathrm{NV}$ can occur at any step from manufacturing to final use including transport, storage, distribution, and preparation for cryopreservation. During a pandemic involving a respiratory virus, as we are presently experiencing, this risk cannot be underestimated. The use of contaminated LN2/ $\mathrm{NV}$ enhances risks virus awakening and contamination of warmed samples, the local environment, and operators [1]. In the immediate vicinity of tanks, dewars, dry shippers, and vitrification boxes, aerosol mist particles are present near LN2 surface, due to condensation, evaporation, and floating particles [2]. For this reason, we believe

Lucia De Santis

desantis.lucia@hsr.it

1 Centro Scienze Natalità, IRCCS Ospedale San Raffaele, Vita-Salute San Raffaele University, Via Olgettina, 60, 20132 Milan, Italy

2 GynePro Medical Centers, NextClinics International, Via T. Cremona, 8, 40137 Bologna, Italy

3 European Hospital, Center for Reproductive Medicine, Via Portuense 700, 00149 Rome, Italy that time has come to pay more attention to the putative risk of environmental contamination rather than only on the hypothetical presence of SARS-CoV-2 in gametes and embryos present in ART clinical centers. It should be further emphasized that environmental nitrogen-mediated contamination can also infect reproductive cells during handling or vitrification and warming, irrespective of the fact we are using open or closed carriers. This concept finds momentum in the recent observation of ACE2 and CD147 receptors on the cell membranes of preimplantation embryos, despite the fact that human oocytes and embryos are considered to be poor vectors for infections [3].

The question of whether the presence of SARS-CoV-2 in cryopreserved samples represents a source of crosscontamination during storage was recently addressed. Since very little is known about the SARS-CoV-2, the authors concluded that we need to envisage safer and more protective measures, including the use of vitrification closed systems and LN2 sterilization to minimize viral exposure during cryopreservation and cryostorage [4].

Taking this perspective, it is necessary to carefully evaluate whether the introduction of new devices, aimed at minimizing theoretical risks, can modify laboratory performance. The efficiency of vitrification remains in fact the goal of cryopreservation and, ultimately, that of clinical outcome of ART treatments.

\section{Declarations}

Competing interests Dr Parmegiani reports fees from Fujifilm-Irvine and Biopsybell and is shareholder of Nterilizer Srl. Dr De Santis and Dr Scarica have nothing to disclose

\section{References}

1. Parmegiani L, Vajta G. Letter: COVID-19 in liquid nitrogen: a potential danger still disregarded. Hum Reprod. 2021;36(1):260. 
2. Lee BU. Cryogenic aerosol generation: airborne mist particles surrounding liquid nitrogen. Int $\mathrm{J}$ Environ Res Public Health. 2020;17(3):1071.

3. Essahib W, Verheyen G, Tournaye H, Van de Velde H. SARS-CoV2 host receptors ACE2 and CD147 (BSG) are present on human oocytes and blastocysts. J Assist Reprod Genet. 2020;37(11):265760 .
4. Pomeroy KO, Schiewe MC. Cryopreservation and IVF in the time of Covid-19: what is the best good tissue practice (GTP)? J Assist Reprod Genet. 2020;37(10):2393-8.

Publisher's note Springer Nature remains neutral with regard to jurisdictional claims in published maps and institutional affiliations. 